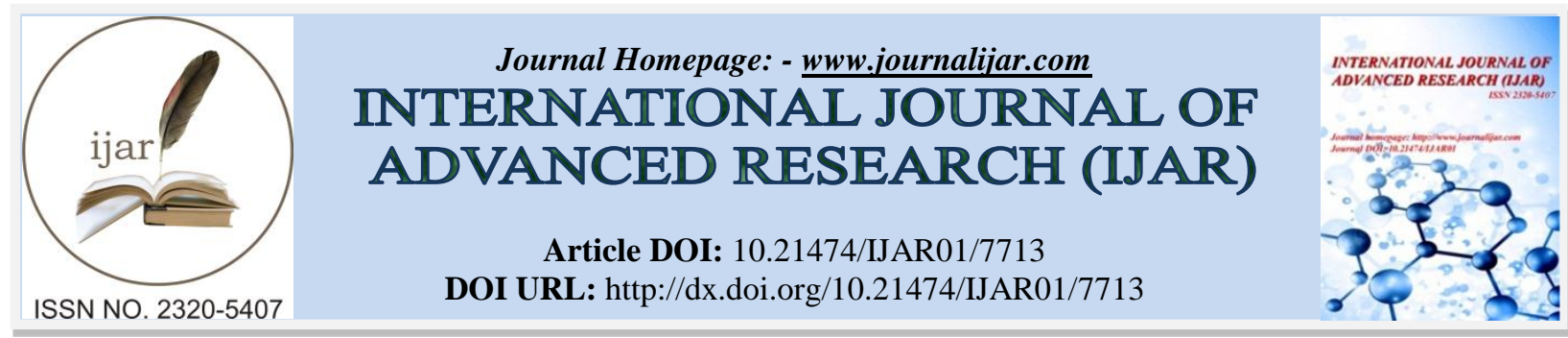

RESEARCH ARTICLE

\title{
NEW INDICES FOR DIFFERENTIATION BETWEEN IRON DEFICIENCY ANEMIA AND BETA THALESSEMIA TRAIT, A STUDY IN CHILDREN.
}

Muna Abdulmueen Abdullah.

Bsc. In haematology, Master of Science in haematopathology.

\section{Manuscript Info}

\section{Manuscript History}

Received: 20 July 2018

Final Accepted: 26 August 2018

Published: September 2018

\section{Keywords:-}

New indices, Iron deficiency anemia, Thalassemia trait.

\section{Abstract}

Background: The two most frequent types of microcytic hypochromic anemia in developing countries are beta thalassemia trait ( -TT) and iron deficiency anemia (IDA). Several indices using blood cell count parameters have been suggested to differentiate between two.

Aim of study: In this study, we compared the ability of different three indices (Mentzer index, RDWI and MCI) to distinguish -TT from IDA by calculating their sensitivity, specificity, positive predictive value (PPV), negative predictive value (NPV) and Youden's index values.

Methods: A total of 98 carefully selected children aged 1.0-17 years were evaluated. We calculated 3 discrimination indices in all patients with hemoglobin $(\mathrm{Hb})$ values of $3.8-11.7 \mathrm{~g} / \mathrm{dL}$. None of the subjects had a combined case of IDA and -TT. The patient groups were evaluated according to red blood distribution width index; the Mentzer index and Matos and Carvalho index (MCI).

Results: The Mentzer index was the most reliable index, as it had the highest sensitivity (96.06\%), specificity (82.98\%), and Youden's index (79.04\%) for detecting -TT; this was followed by the RDW index $(87.23 \%, 86.27 \%$, and $73.5 \%$, resp.) and MCI $(91.49 \%, 80.04 \%$, and $71.53 \%)$.

Conclusion: The Mentzer index provided the highest reliabilities for differentiating -TT from IDA.

Copy Right, IJAR, 2018,. All rights reserved.

\section{Introduction:-}

Anemia affects about 800 million children and women world-wide. The most common causes of anemia are iron deficiency anemia (IDA) and - thalassemia trait ( $-\mathrm{TT}) .{ }^{(1-3)}$ According to World Health Organization (WHO) estimates in 2004, IDA resulted in 273,000 deaths and the loss of 19.7 million disability-adjusted life years, accounting for $1.3 \%$ of the global total, with $97 \%$ occurring in low- and middle-income countries. ${ }^{(3,4)}$

Anemia resulting from lack of sufficient iron to synthesize hemoglobin is the most common hematological disease in infants and children. It has been estimated that $30 \%$ of the global population suffers from iron deficiency anemia (IDA), and most of those affected live in the developing countries.

Microcytic anemia in a case of thalassemia results from impaired globin chain synthesis and decreased hemoglobin $(\mathrm{Hb})$ synthesis, resulting in microcytosis and hypochromia; $1.5 \%$ of the world's population carries genes for -thalassemia ${ }^{(5)}$. Individuals with the beta thalassemia trait ( - are usually asymptomatic and may be 
unaware of their carrier status unless diagnosed by testing. -TT is the most common type of hemoglobinopathy transmitted by heredity. It is estimated that about 50\% of the world's population with -TT are in Southeast Asia; it is also common in the Mediterranean region, the Middle East, Southeast Asia, Southwest Europe, and Central Africa ${ }^{(6)}$. Due to the migration and intermarriage of different ethnic populations, -TT is found in people with no obvious ethnic connection to the disorder. A definitive differential diagnosis between -TT and IDA is based on the result of HbA2 electrophoresis, serum iron levels, and a ferritin calculation ${ }^{(7)}$.

A number of studies have revealed that derived red cell indices including red cell distribution width (RDW) can be very helpful in differentiation of anisocytosis caused by IDA or --TT and a recently added red cell distribution width index (RDWI) provide valuable help to the attending physician. ${ }^{(8-10)}$ RDWI is more advantageous as all the discriminating factors including RBC count, MCV (mean corpuscular volume) and RDW are incorporated in its formula. ${ }^{(1)}$ Derived indices like an index of RDW can be calculated using the automated blood cell counters for differentiation between IDA and -TT. The RDW measures the average RBC size variation, calculated by the RBCs histogram and is calculated as a standard statistical value, the coefficient of variation of the volume distribution. According to few studies, RDW is the first index to become abnormal in iron deficiency.(12-14) A rather improvised index, RDWI has proven to be a reliable discrimination index in the differentiation of -TT and IDA. ${ }^{(11)}$ According to the ROC curve, the RDWI conferred with a cut off value of 220 to discriminate between IDA and -TT. If the index is $<220$, the patient is tabulated as -TT patient, while values $>220$ classified as a IDA. ${ }^{(11)}$

The Mentzer index is calculated using mean corpuscular volume and red blood cell count. If (MCV (fl) / RBC count (millions per microliter)) is less than 13, -TT is said to be more likely. If the result is greater than 13 , then iron-deficiency anaemia is said to be more likely. ${ }^{(15)}$

The adjusted formula of the new index was Matos and Carvalho index (MCI). According to the ROC curve, the MCI conferred with a cut off value of 23.85 to discriminate between IDA and -TT. If the index is $<23.85$, the patient is tabulated as an IDA patient, while those with $>23.85$ are classified as a $-\mathrm{TT}$. ${ }^{(15)}$

In this study, we compared the ability of different 3indices (Mentzer index, RDWI and MCI) to distinguish -TT from IDA by calculating their sensitivity, specificity, positive predictive value (PPV), negative predictive value (NPV) and Youden's index values.

\section{Subjects, Material and Methods:-}

Present cross-sectional study was conducted at Pathology department of a Children Teaching Hospital from January 2018 to July 2018 at Karbala city. We retrospectively analyzed 98 children with microcytic anemia (mean age: $7.87 \pm 4.87$ years, range: 1-17 years). Samples were obtained from 48 boys and 50 girls with no clinical symptoms of acute or chronic inflammation or infectious diseases. None of them had received a transfusion or had an acute bleeding episode in the previous month. The samples were obtained during the course of routine analysis and collected in EDTA anticoagulant tubes. Red blood cell (RBC) count and red blood cell distribution width (RDW) were assessed on a Sysmex - XP 300 Hematology Analyzer.

Serum iron (SI), serum iron binding capacity, serum ferritin, and HbA2 values were determined in all children. $\mathrm{HbA} 2$ was detected by high-performance liquid chromatography (Bio Rad D10). SI and total iron binding capacity (TIBC) were determined by CoBas Integra 400 plus, and ferritin was measured by CoBas e 411 Analyzer. Serum ferritin level of $<10 \mu \mathrm{g} / \mathrm{dl}$ was taken as cut off for diagnosis of iron deficiency anaemia. The increase in HbA2 levels $(>3.5 \%)$ is the most significant parameter for identifying beta thalassemia carriers. ${ }^{(16)}$ Patients with -TT and concomitant iron deficiency may show normal HbA2 levels. ${ }^{(17)}$ Therefore, none of the subjects in the present study had both IDA and -TT.

The 3 discrimination indices used in the evaluation were calculated and are summarized in Table 1. Sensitivity, specificity, positive predictive value (PPV), negative predictive value (NPV), and Youden's index were calculated for each measure. The results were analyzed statistically by using SPSS version 16.0. An independent sample -test was performed to detect differences between the two groups of anemic children. values $<0.05$ were considered significant. 
Table 1:- Different RBC indices and mathematical formulas used to differentiate between -TT and IDA.

\begin{tabular}{|l|l|}
\hline Hematological index & Formula \\
\hline Mentzer index (MI) & MCV/RBC \\
\hline RDWI & MCV $\times$ RDW/RBC \\
\hline MCI & $(1.91 \times \mathrm{RBC})+(0.44 \times \mathrm{MCHC})$ \\
\hline
\end{tabular}

\section{Results:-}

Hematological parameters:

The median and interquartile ranges of CBC parameters for the 98 patients ( -TT and IDA groups) enrolled in the study were calculated. $\mathrm{RBC}, \mathrm{Hb}$, and $\mathrm{MCHC}$ values for -TT patients were significantly higher than those observed for IDA patients whereas $\mathrm{MCH}$, RDW and the platelet count were significantly lower than those observed for IDA patients. Hematological parameters of the two study groups are shown in Table 1.

Table 2:- Hematological parameters of study groups.

\begin{tabular}{|c|c|c|c|c|c|c|c|c|c|}
\hline parameter & & \multicolumn{3}{|c|}{-TT (n:51) } & \multicolumn{4}{|c|}{ IDA $(n: 47)$} & \multirow{3}{*}{$\begin{array}{l}\text { p- value } \\
<0.05\end{array}$} \\
\hline & \multicolumn{2}{|c|}{ Range } & \multirow{2}{*}{\multicolumn{2}{|c|}{$\begin{array}{l}\text { mean } \pm \text { SD } \\
5.9 \pm 0.62\end{array}$}} & \multicolumn{2}{|c|}{ Range } & \multicolumn{2}{|c|}{ mean \pm SD } & \\
\hline $\mathrm{RBC}\left(\times 10^{6} 1\right)$ & 4.5 & -7.6 & & & 2.6 & -5.2 & 3.3 & \pm 0.57 & \\
\hline $\mathrm{Hb}$ (gm dl) & 8.6 & -11.7 & 10.4 & \pm 0.83 & 3.8 & -11.3 & 8.1 & \pm 1.9 & $<0.05$ \\
\hline $\mathrm{MCV}$ (fl) & 45.5 & -75.2 & 63.1 & \pm 5.9 & 44.5 & -76 & 62.5 & \pm 7.3 & $<0.05$ \\
\hline $\mathrm{MCH}(\mathrm{pg})$ & 11.2 & -24.2 & 17.5 & \pm 3.4 & 12.7 & -28.8 & 19.9 & \pm 2.6 & $<0.05$ \\
\hline MCHC (gm/dl) & 29.7 & -34.2 & 31.6 & \pm 1.1 & 22.9 & -33.3 & 27.9 & \pm 2.7 & $<0.05$ \\
\hline RDW (\%) & 13.6 & -27.4 & 16.7 & \pm 2.7 & 10.8 & -29.8 & 19.5 & \pm 4.0 & $<0.05$ \\
\hline Platelets $\left(10^{3} / \mathrm{L}\right)$ & \multicolumn{2}{|c|}{$151-525$} & \multicolumn{2}{|c|}{$340 \pm 82.2$} & \multicolumn{2}{|c|}{$197-835$} & \multicolumn{2}{|c|}{$426.8 \pm 162.2$} & $<0.05$ \\
\hline
\end{tabular}

Validation of the indices:

The values of each index required to distinguish between -TT and IDA and the number and proportion of correctly identified patients (true positives) calculated using these indices are shown in Table 3.

Table 3:- Results obtained from each discrimination index and correctly identified number of the children.

\begin{tabular}{|l|l|l|l|l|}
\hline & & & Total number & \\
\hline Indices & - TT $(: 51)$ & IDA ( : 47) & of correctly & Correctly \\
\hline (cutoffs) & & & diagnosed & diagnosed $(\%)$ \\
\hline & & & children & \\
\hline Mentzer & & & & \\
\hline- TT $<13$ & 49 & 8 & $88(49+39)$ & $89.8 \%$ \\
\hline IDA $>13$ & 2 & 39 & & \\
\hline RDWI & & & & $86.7 \%$ \\
\hline -TT <220 & 44 & 6 & $85(44+41)$ & \\
\hline IDA $>220$ & 7 & 41 & & $85.7 \%$ \\
\hline MCI & & & & \\
\hline -TT < 23.85 & 41 & 4 & $84(41+43)$ & \\
\hline IDA $>23.85$ & 4 & 43 & & \\
\hline
\end{tabular}

As indicated in Table 4, none of the indices studied demonstrated 100\% precision in recognizing -TT.

The Mentzer index showed good sensitivity, specificity, and Youden's index values of 96.06\%, 82.98\%, and $79.04 \%$, respectively. When the Mentzer index was calculated, 98 children with microcytic anemia (89.8\%) were correctly diagnosed.

Red cell distribution width index showed the sensitivity and specificity of $87.23 \%$ and $86.27 \%$, respectively with Youden's index of 73.5\% (Table 4). Matos and Carvalho index showed higher sensitivity (91.49\%) but a lower specificity (80.04\%) and Youden's index (71.51\%) (Table 4). 
Table 4:- Sensitivity, specificity, positive predictive value (PPV), negative predictive value (NPV), and Youden's index of three indices to discriminate between -TT and IDA in 98 children.

\begin{tabular}{|l|l|l|l|l|l|}
\hline Indices & Sensitivity\% & Specificity\% & PPV\% & PPV\% & Youden's \\
\hline & & & & & index \\
\hline Mentzer & & & & & \\
\hline -TT & 96.06 & 82.98 & 85.96 & 95.12 & \\
\hline IDA & 82.98 & & & & 79.04 \\
\cline { 3 - 6 } & & 96.06 & 95.12 & 85.96 & \\
\hline RDWI & & & & & \\
\hline -TT & 86.27 & 87.23 & 88.00 & 85.42 & \\
\hline IDA & & & & & 73.50 \\
\hline MCI & 87.23 & 86.27 & 85.42 & 88.00 & \\
\hline -TT & 80.04 & & & & \\
\hline & & 91.49 & 91.11 & 84.31 & 7.53 \\
\hline IDA & 91.49 & & & & \\
\hline
\end{tabular}

\section{Discussion:-}

-TT and IDA are among the most common types of microcytic anaemia encountered by pediatricians. Distinguishing -TT from IDA has important clinical implications because each disease has an entirely different cause, prognosis, and treatment. Misdiagnosis of -TT has consequences for potential homozygous offspring. Up to now, many investigators have used different mathematical indices to distinguish -TT from IDA using only a complete blood count. This process helps to select appropriate individuals for a more detailed examination; however, no study has found $100 \%$ specificity or sensitivity for any of these RBC indices. Our data (Table showed significant differences between the hematological and biochemical parameters of -TT and IDA children.

The differentiation between -TT and IDA, requires $\mathrm{Hb}$ A2 estimation by HPLC, examination of a peripheral blood film, serum ferritin, iron, TIBC, and transferrin saturation. But being relatively expensive and time consuming, it is preferred to rely on simple and already available information. Many investigators have used different mathematical indices to distinguish -TT from IDA using complete blood count. This process helps to select appropriate individuals for a more detailed examination.

According to our data, the Mentzer index (Table 4), of the index was very high (96.06\%) for identifying -TT patients had the highest Youden's index for correctly distinguishing -TT and IDA at 79.04\%. When the Mentzer index was calculated, $89.8 \%$ of children with microcytic anemia were correctly diagnosed, this comparable to other studies. ${ }^{(8,18)}$

Red cell distribution width (RDW) (Table 2) is provided in CBCs by the automated analyzers and can be utilized in the association with a derived value RDWI to distinguish IDA and -TT. ${ }^{19)}$ RDWI denotes anisocytosis, its value is increased in IDA, and it is near normal or mildly increased in -

RDWI came out as good discriminator between TT and IDA. The sensitivity and specificity of RDWI in the detection of -TT were found $86.27 \%$ and $87.23 \%$, respectively and the sensitivity and specificity for the detection of IDA were $87.23 \%$ and $86.27 \%$, respectively. These results are consistent with the findings of other relevant studies. ${ }^{(8,14,20)}$

MCI (Table 4) was also evaluated for discriminating between IDA and - This formula produced high sensitivity and excellent diagnostic accuracy. MCI also revealed high PPV (84.31\%), showing good applicability as a screening tool in the clinical practice. An important result obtained for MCI is the high sensitivity to detect IDA (91.49\%). As sensitivity is a parameter that indicates the proportion of individuals correctly identified with the disease, the high sensitivity of the MCI in the detection of IDA indicates that it is a good tool to identify this disorder. $^{(21)}$ 


\section{Conclusion:-}

In closure, the automated cell-count-based indices, particularly the Mentzer index, RDWI and MCI are easily available and reliable methods for detecting IDA \& differentiating it from -TT. According to our results, the sensitivity and Youdens index was the highest with the Mentzer index. Both RDWI and MCI, the new indices also showed very high sensitivity and PPV.

\section{Recommndation:-}

These appearing to be a reliable and useful index for initial screening of microcytic hypochromic anemia. This would result in a significant cost saving for the health system, especially advantageous in underdeveloped and developing countries with limited financial resources.

\section{References:-}

1. Kassebaum NJ, Jasrasaria R, Naghavi M, Wulf SK, Johns N,Lozano R, et al. A systematic analysis of global anemia burden from 1990 to 2010. Blood. 2014; 123(5):615-24.

2. Pasricha SR. Anemia: a comprehensive global estimate. Blood.2014; 123(5):611-2.

3. World Health Organization. The global prevalence of anaemia in 2011. Available http://www.who.int/nutrition/publications/micronutrients/global prevalence anaemia 2011/en/.

4. Mathers C, Steven G, Mascarenhas M. Global health risks: mortality and burden of disease attributable to selected major risks. Geneva, Switzerland: World Health Organization; 2009.

5. Rathod D. A., Kaur A., Patel V. et al., "Usefulness of cell counter based parameters and formulas in detection of -thalassemia trait in areas of high prevalence," American Journal of Clinical Pathology.2007; vol. 128 , no. 4 , pp. $585-589$.

6. E. Urrechaga, L. Borque, and J. F. Escanero, "The role of automated measurement of RBC subpopulations in differential diagnosis of microcytic anemia and -thalassemia screening," American Journal of Clinical Pathology. 2011; vol. 135, no. 3, pp. 374-379.

7. Thomas C. and Thomas L., "Biochemical markers and hematologic indices in the diagnosis of functional iron deficiency," Clinical Chemistry.2002; vol. 48, no. 7, pp. 1066-1076.

8. Vehapoglu A, Ozgurhan G, Demir AD, Uzuner S, Nursoy MA, Turkmen S, et al. Hematological indices for differential diagnosis of beta thalassemia trait and iron deficiency anemia. Anemia. 2014; 10 (5):1-7.

9. Bordbar E, Taghipour M, Zucconi BE. Reliability of different RBC indices and formulas in discriminating between $\beta$-Thalassemia minor and other microcytic hypochromic cases. Mediterr J Hematol Infect Dis. 2015; 7(1):1-12.

10. Huang TC, Wu YY, Chen YG, Lai SW, Wu SC, Ye RH, et al. Discrimination Index of Microcytic Anemia in Young Soldiers: A Single Institutional Analysis. Plo S One. 2015; 10(2):1-10.

11. Ismail M, Patel NG. Evaluation of the Diagnostic Accuracy of Twelve

12. Discrimination Indices for differentiating $\beta$-thalassemia Trait from Iron Deficiency Anemia. Indian J Public Health Res Dev. 2016; 7(1):104-109.

13. Verma S, Gupta R, Kudesia M, Mathur A, Krishan G, Singh S. Coexisting iron deficiency anemia and Beta thalassemia trait: effect of iron therapy on red cell parameters and hemoglobin subtypes. ISRN Hematol. 2014; 12(3):1-4.

14. Hoffmann JJ, Urrechaga E, Aguirre U. Discriminant indices for distinguishing thalassemia and iron deficiency in patients with microcytic anemia: a meta-analysis. CCLM. 2015; 53(12):1883-94 Plengsuree S, Punyamung M, Yanola J, Nanta S, Jaiping K, Maneewong

15. $\mathrm{K}$, et al. Red cell indices and formulas used in differentiation of $\beta$-thalassemia trait from iron deficiency in Thai adults. Hemoglobin. 2015; 39(4):235-9.

16. Mentzer WC Jr. Differentiation of iron deficiency from thalassaemia trait. Lancet. 1973; 1(7808):882.

17. Thein SL and Rees D. Haemoglobin and the inherited disorders of globin synthesis. In: Hoffbrand AV, Higgs DR, Keeling DM and Mehta AB (eds). Postgraduate haematology. $11^{\text {th }}$ Edition. Wiely Backwell 2016; p 85.

18. Wild BJ and Bain BJ. Investigation of variant haemoglobins and thalassaemias. In: Bain BJ, Bates I, Lewis SM and Laffan MA. (eds). Dacie and Lewis Practical Haematology. $12^{\text {th }}$ Edition. US: Elsevier 2017. P 308.

19. Patra S, Adhikari BC. International Journal of Scientific research.2017; vol.6, no. 2272, pp 40- 41.

20. Rahim F and Keikhaei B. Better differential diagnosis of iron deficiency anemia from beta-thalassemia trait. Turkish J Hematol. 2009; 26 (3):138-

21. 45 . 
22. Ehsani M.A, Shahgholi E, Rahiminejad M.S, Seighali F, and Rashidi A. A new index for discrimination between iron deficiency anemia and beta-thalassemia minor: results in 284 patients. Pakistan J Biological Sci. 2009; 12(5):473-5.

23. Arora1 S., Rana D., Kolte S., Dawson L and Dhawan I. Validation of new indices for differentiation between iron deficiency anemia and beta thalessemia trait, a study in pregnant females. International Journal of Scientific Reports. 2018 Feb; 4 (2):26-30. 